\title{
MORFOLOGI CERITA RAKYAT SOBEY KORORSRI (PENERAPAN TEORI NARATOLOGI VLADIMIR PROPP)
}

\author{
MORPHOLOGY OF SOBEY'S FOLKTALE KORORSRI \\ (TO APPLY VLADIMIR PROPP'S NARATOLOGY THEORY)
}

\author{
Ummu Fatimah Ria Lestari \\ Balai Bahasa Provinsi Papua dan Provinsi Papua Barat \\ Jalan Yoka Waena, Distrik Heram, Jayapura, Papua 99358. \\ Telepon: 0811481082, Pos-el: ufrl.82@gmail.com
}

\begin{abstract}
This research discusses about morphology of Sobey's folktale Kororsri based on Propp theory. Its problem is how about morphology of Sobey's folktale Kororsri based on Propp theory. This research used qualitative method. Its data was collected by library research. In its analyzing, the researcher analyzed the morphology ofSobey's folktale Kororsri by using Propp's Structural theory. The results of this research the morphology of this folktale consist of: 21 (twenty one) functions, 3 (three) pattern naratology, and 6 (six) speres of actions.
\end{abstract}

Keywords: morphology, folktale, Kororsri

\begin{abstract}
Abstrak
Penelitian ini mengkaji morfologi cerita rakyat Sobey Kororsri berdasarkan teori Struktur Propp. Masalah yang akan dibahas dalam penelitian ini adalah bagaimana morfologi cerita rakyat Sobey Kororsridalam teori Struktur Propp. Penelitian ini menggunakan metode kualitatif. Teknik pengumpulan datanya melalui studi pustaka (dokumentasi). Dalam pelaksanaannya, penelitian ini menganalisis morfologi cerita rakyat Sobey Kororsriberdasarkan teori dan metode penelitian Struktur Fungsi Propp. Hasil analisis penelitian ini adalah ditemukan 21 (dua puluh satu) fungsi naratif, 3 (tiga) pola cerita, dan 6 (enam) lingkaran tindakan dalam cerita rakyat.
\end{abstract}

Kata kunci: morfologi, cerita rakyat, Kororsri

\section{Pendahuluan}

Masyarakat Sobey (Sobei) hidup pada tiga wilayah utama, yakni Sawar, Bagaiserwar, dan kota Sarmi. Selain itu, mereka ada juga yang menempati beberapa pulau, seperti Liki-liki, Wakde, Yamna, Anus, dan Podena. Mereka dikelompokkan dalam suku bangsa Sobey. Mereka merupakan salah satu suku bangsa besar di Kabupaten Sarmi, Provinsi Papua. Secara sosiolinguistik, mereka menuturkan bahasa Sobey sebagai bahasa ibu. Bahasa Sobey termasuk dalam golongan bahasa Austronesia.

Samakori, et.al (2012: 45) juga mengemukakan, Suku Sobey mendiami wilayah pantai barat ke arah timur, mulai dari kampung Maseb wilayah pantai 
barat, kepulauan Kumamba (pulau Liki, pulau Tengah, pulau Armo, pulau Sarmi) sampai ke pulau Yamna, Masimasi, Anus, dan Podena.

Joyce Stemer (dalam Lekitoo dan Djoht, 2005: 100) mengungkapkan bahwa secara kultural, orang Sobey sangat memperhatikan identitas dan harga dirinya. Struktur kekerabatan dan organisasi sosial membawahi nilai-nilai kebebasan dan hak-hak perseorangan. Hal ini menciptakan situasi yang menghasilkan persaingan marga dan persaingan pada saudara kandung. Posisi seseorang dalam hidup dibentuk lewat hubungan langsung, tetapi seseorang harus berjuang untuk mendapat posisi di antara saudara-saudara (sekandung) tingkat horizontal atau generasi. Walaupun kerja sama di antara marga terjadi dalam berbagai aktivitas seperti mengerjakan kebun, membangun rumah, mengadakan pertemuan-pertemuan sosial dalam keluarga dan pesta-pesta. Akan tetapi, persaingan marga, garis/silsilah keturunan dan malahan antarsaudara kandung. Kecerdikan dan manipulasi merupakan sarana yang digunakan untuk mencapai sasaran.

Sepengetahuan peneliti, penelitian cerita rakyat Sobey masih terbatas pada tahap inventarisasi dan penerjemahan. Penelitian tentang struktur formal, apalagi morfologi ceritanya, belum pernah dilakukan. Olehnya, hal itu menjadi latar belakang sehingga penelitian ini dilakukan. Cerita rakyat Kororsri adalah salah satu cerita rakyat Sobey dari Pulau Anus. Selain cerita rakyat (folktale), orang Sobey di Pulau Anus juga memiliki banyak kekayaan sastra lisan. Cerita rakyat Kororsri ini dipilih karena cerita rakyat ini sudah ditulis dan dipublikasikan dalam bentuk buku. Selain itu, cerita ini begitu dikenal oleh masyarakat Sarmi secara umum.

Berdasarkan latar belakang yang telah dikemukakan sebelumnya, penelitian ini bertujuan untuk menganalisis dan mendeskripsikan morfologi cerita rakyat Sobey Kororsri dengan menerapkan teori Fungsi Propp. Sementara itu, kegunaan penelitian ini meliputi kegunaan yang praktis dan kegunaan yang bersifat teoretis. Penelitian ini diharapkan bermanfaat bagi: 1) Dosen pengasuh mata kuliah Bahasa dan
Sastra sebagai referensi teoretis; 2) Peneliti untuk kepentingan kepentingan riset sastra lisan; 3) Pemerintah untuk penetapan kebijakan dan peraturan di daerah; 4) Suku Sobey sebagai sikap mempertahankan budaya Sobey; dan 5) Guru Bahasa dan Sastra sebagai bahan ajar dalam pembelajaran sastra dan pembelajaran muatan lokal pada pendidikan dasar.

Bila dibandingkan dengan beberapa daerah lain dalam Provinsi Papua, penelitian tentang morfologi cerita rakyat yang telah dilakukan antara lain 1) Struktur Cerita Rakyat dalam Kehidupan Masyarakat Suku Mee Papua: Penerapan Teori Vladimir Propp olehAndreas Yobee tahun 2006. Hasil penelitian ini merupakan tesisnya yang diterbitkan oleh Arga Fuji Press; 2) Morfologi Cerita Rakyat Tepera tahun 2013 oleh Sriyono dan Ummu Fatimah R.L. dari Balai Bahasa Provinsi Papua dan Provinsi Papua Barat(belum dipublikasikan); 2) Morfologi Cerita Rakyat Ormu oleh Ummu Fatimah R.L. Penelitian ini dipublikasikan dalam jurnal Multilingual Balai Bahasa Provinsi Sulawesi Tengah vol. XII, no. 1, Juni 2013, hal. 128--139; dan 3) Morfologi Sastra Lisan Tobati oleh Sriyono. Penelitianini dipublikasikan dalam jurnal Metasastra Balai Bahasa Provinsi Jawa Barat tahun 2014; 4) Morfologi Cerita Rakyat Isirawa tahun 2014 oleh Ummu Fatimah R.L. et.al. dari Balai Bahasa Provinsi Papua dan Provinsi Papua Barat (belum dipublikasikan); 5) Morfologi Cerita Rakyat Biak Manarmakeri tahun 2014 oleh Ummu Fatimah R.L. dari Balai Bahasa Provinsi Papua dan Provinsi Papua Barat (belum dipublikasikan); 6) Morfologi Cerita Rakyat Tabu Elseng Monabi tahun 2014 oleh Ummu Fatimah R.L. dari Balai Bahasa Provinsi Papua dan Provinsi Papua Barat (belum dipublikasikan); 7) Morfologi Cerita Rakyat Arso Watuwe tahun 2014 oleh Ummu Fatimah R.L. dari Balai Bahasa Provinsi Papua dan Provinsi Papua Barat (belum dipublikasikan); dan 8) Morfologi Cerita Rakyat Asmat Jipi tahun 2014 oleh Ummu Fatimah R.L. dari Balai Bahasa Provinsi Papua dan Provinsi Papua Barat (belum dipublikasikan). 


\section{Teori Penelitian}

\subsection{Teori Morfologi Propp}

Endraswara (2013: 60) menyatakan, Propp adalah tokoh yang pertama menangani cerita rakyat Rusia. Ia bertolak dari gagasan studi linguistik, sehingga membahas teks dari suatu lingkup wacana. Olehnya, teori dan metode penelitian cerita rakyat yang ia cetuskan dikenal sebagai morfologi cerita rakyat. Lebih lanjut, Taum(2011: 122) menambahkan, Propp adalah tokoh strukturalis pertama yang melakukan kajian secara serius terhadap struktur naratif, sekaligus memberikan makna baru terhadap dikotomi fabula (cerita)dan sjuzhet (alur).

Propp (dalam Susanto, 2012: 111; Lestari, 2013: 133) mengembangkan teori yang berasal dari konsep formalisme Rusia yang berhubungan dengan dengan alur dari peristiwa atau aksi. Propp menggunakan pendekatan yang bergerak dari etik menuju pendekatan emik terhadap struktur naratif. Propp lebih menekankan perhatiannya pada motif naratif terpenting, yakni tindakan atau perbuatan (action). Tindakan tersebut dinamakan fungsi. Propp juga mengemukakan bahwa yang terpenting adalah pelaku, bukan tokoh. Lebih tegasnya, yang terpenting menurut Propp adalah tindakan pelaku yang terdapat dalam fungsi. Fungsi adalah tindakan seorang tokoh yang dibatasi dari segi maknanya untuk jalannya suatu cerita. Propp juga menjelaskan bahwa suatu cerita pada dasarnya memiliki konstruksi. Konstruksi yang terdiri atas motif-motif memiliki tiga unsur, yakni pelaku, perbuatan, dan penderita. Ketiga unsur itu dapat dibagi menjadi dua, yakni unsur yang tetap dan unsur tidak tetap. Unsur tetap adalah perbuatan dan unsur tidak tetapnya adalah pelaku dan penderita. Menurutnya, unsur yang terpenting adalah unsur yang tetap.

Propp (dalam Suwondo, 2011: 55--59; Lestari, 2013: 133) berpendapat bahwa peneliti sebelumnya banyak melakukan kesalahan dan sering membuat kesimpulan yang tumpang tindih. Berdasarkan penelitiannya terhadap seratus dongeng Rusia yang disebutnya fairytale, Propp akhirnya memper- oleh simpulan (1) anasir yang mantap dan tidak berubah dalam sebuah dongeng bukanlah motifatau pelaku, melainkan fungsi, lepas dari siapa pelaku yang menduduki fungsi itu; (2) jumlah fungsi dalam dongeng terbatas; (3) urutan fungsi dalam dongeng selalu sama; dan (4) dari segi struktur semua dongeng hanya mewakili satu tipe. Sehubungan dengan simpulan (2), Propp menyatakan bahwa paling banyak sebuah dongeng terdiri atas 31 fungsi. Namun, ia juga menyatakan bahwa setiap dongeng tidak selalu mengandung semua fungsi itu karena banyak dongeng yang ternyata hanya mengandung beberapa fungsi. Fungsi-fungsi itulah, berapa pun jumlahnya, yang membentuk kerangka pokok cerita.

Teeuw (1988: 292) mengungkapkan bahwa hasil analisis Propp terhadap dongeng Rusia tersebut cukup mengejutkan. Sebab bila benar dan harus diterima, berarti Propp berhasil memberikan satu dasar untuk penggolongan dongeng dan cerita rakyat lain yang sungguh-sungguh struktural dan berlaku umum, jadi berhasil mencapai hasil ilmiah yang gilang-gemilang. Pada prinsipnya, inilah pendekatan yang sangat legitim dan harus dipuji.

Teeuw juga menyatakan (1988: 293), pendapat de Saussure cukup umum telah disetujui bahwa penelitian struktur harus mendahului penelitian sejarah, sebab perbandingan perkembangan sejarah baru mungkin kalau kita mengetahui setepat mungkin fungsi unsur-unsur sebuah cerita dalam keseluruhannya, transformasi baru menjadi jelas berdasarkan pemahaman makna bagian-bagian dan motif-motif dalam keseluruhan sebuah cerita.

Tiga puluh satu fungsi yang dimaksudkan oleh Propp adalah seperti di bawah ini. Untuk mempermudah perbuatan skema, Propp memberikan tanda atau lambang khusus pada setiap fungsi (barangkali, kalau kita mengganti lambang itu sesuai dengan keinginan kita, tentu juga tidak ada salahnya). Adapun fungsi-fungsi dan lambangnya sebagai berikut. 


\begin{tabular}{|c|c|c|}
\hline No. & Fungsi & Lambang \\
\hline 1. & Absentation $=$ ketiadaan & $\beta$ \\
\hline 2. & Interdiction = larangan & $\gamma$ \\
\hline 3. & Violation $=$ pelanggaran & $\delta$ \\
\hline 4. & Reconnaissance $=$ pengintaian & $\varepsilon$ \\
\hline 5. & Delivery $=$ penyampaian (informasi) & $\xi$ \\
\hline 6. & Fraud $=$ penipuan (tipu daya) & $\eta$ \\
\hline 7. & Complicity $=$ keterlibatan & $\theta$ \\
\hline 8. & Villainy $=$ kejahatan & A \\
\hline $8 \mathrm{a}$. & Lack $=$ kekurangan (kebutuhan) & $\mathrm{a}$ \\
\hline 9. & $\begin{array}{l}\text { Mediation, the connective incident }= \\
\text { perantaraan, peristiwa penghubung }\end{array}$ & $\mathrm{B}$ \\
\hline 10. & Beginning countraction $=$ penetralan (tindakan) dimulai & $\mathrm{C}$ \\
\hline 11. & Departure $=$ keberangkatan (kepergian) & $\uparrow$ \\
\hline 12. & The first function of the donor $=$ fungsi pertama donor (pemberi) & $\mathrm{D}$ \\
\hline 13. & The hero's reaction = reaksi pahlawan & $\mathrm{E}$ \\
\hline 14. & $\begin{array}{l}\text { Provition or receipt of a magical agent }= \\
\text { penerimaan unsur magis (alat sakti) }\end{array}$ & $\mathrm{F}$ \\
\hline 15. & Spacial translocation $=$ perpindahan (tempat) & G \\
\hline 16. & Struggle $=$ berjuang, bertarung & $\mathrm{H}$ \\
\hline 17. & Marking $=$ penandaan & $\mathrm{J}$ \\
\hline 18. & Victory $=$ kemenangan & I \\
\hline 19. & $\begin{array}{l}\text { The initial misfortune or lack is liquidated }= \\
\text { Kekurangan (kebutuhan) terpenuhi }\end{array}$ & K \\
\hline 20. & Return $=$ kepulangan $($ kembali $)$ & $\downarrow$ \\
\hline 21. & Pursuit, chase $=$ pengejaran, penyelidikan & $\operatorname{Pr}$ \\
\hline 22. & Rescue $=$ penyelamatan & Rs \\
\hline 23. & Unrecognised arrival $=$ datang tak terkenali & $\mathrm{O}$ \\
\hline 24. & Unfounded claims $=$ tuntutan yang tak mendasar & $\mathrm{L}$ \\
\hline 25. & The difficult task = tugas sulit (berat) & M \\
\hline 26. & Solution $=$ penyelesaian (tugas) & $\mathrm{N}$ \\
\hline 27. & Recognition $=$ (pahlawan) dikenali & Q \\
\hline 28. & Exposure $=$ penyingkapan (tabir) & Ex \\
\hline 29. & Transfiguration $=$ penjelmaan & $\mathrm{T}$ \\
\hline 30. & Punishment $=$ hukuman (bagi penjahat) & $\mathrm{U}$ \\
\hline 31. & Wedding $=$ perkawinan (dan naik tahta) & $\mathrm{W}$ \\
\hline
\end{tabular}


Ketiga puluh satu fungsi itu dapat didistribusikan ke dalam lingkaran atau lingkungan tindakan (speres of action) tertentu. Ada tujuh lingkungan tindakan yang dapat dimasuki oleh fungsi-fungsi yang tergabung secara logis, yaitu (1) villain = lingkungan aksi penjahat; (2) donor, provide = lingkungan aksi donor, pembekal; (3) helper = lingkungan aksi pembantu; (4) the princess and her father= lingkungan aksi fungsi dan ayahnya; (5) dispatcer = lingkungan aksi perantara (pemberangkat); (6) hero = lingkungan aksi pahlawan; dan (7) false hero = lingkungan aksi pahlawan palsu. Melalui tujuh lingkungan tindakan (aksi) itulah frekuensi kemunculan pelaku dapat dideteksi dan cara bagaimana watak pelaku diperkenalkan dapat diketahui.

Menurut Selden (dalam Ratna, 2006: 133), meskipun teori Propp didasarkan atas dongeng-dongeng Rusia, tetapi fungsi-fungsi tersebut dianggap hadir dalam jenis-jenis yang lain, seperti komedi, mitos, epik, roman, dan cerita pada umumnya. Oleh karena itulah, di Indonesia, model penelitian Propp diharapkan dapat memberikan inspirasi dalam upaya untuk mengkaji kekayaan tradisi lisan.

\section{Metode Penelitian}

Penelitian ini menggunakan metode kualitatif. Metode ini memanfaatkan cara-cara penafsiran dengan menyajikannya dalam bentuk deskripsi. Objek penelitian bukan gejala sosial sebagai bentuk substantif, melainkan makna-makna yang terkandung di balik tindakan, yang justru mendorong timbulnya gejala sosial tersebut. Dalam hubungan inilah, Ratna (2006: 46--47) menyatakan bahwa metode kualitatif dianggap persis sama dengan metode pemahaman atau verstehen. Sesuai dengan namanya, penelitian kualitatifmempertahankan hakikat nilai-nilai. Pengumpulan data dilakukan dengan menggunakan teknik dokumentasi. Teknik dokumentasi dilakukan dengan mengumpulkan data berupa dokumen-dokumen yang berhubungan dengan objek yang dianalisis. Pengumpulan data dilakukan melalui studi pustaka.

Analisis data dalam penelitian ini menggunakan teknik analisis morfologi yang dikemukakan oleh Vladimir Propp. Konsep dasar analisis morfologi (analisis struktur naratif) Vladimir Propp adalah fungsi dan peranan pelaku dalam cerita. Cara analisis dimulai dengan memeriksa kembali data-data dan memilah-milahnya berdasarkan jenis dan tipenya. Teknik analisis data disesuaikan dengan penerapan teori Fungsi Vladimir Propp. Teknik tersebut antara lain 1) mengindentifikasi fungsi dalam sebuah dongeng, kemudian fungsi tersebut dimasukkan ke dalam tanda atau lambang khusus yang telah dibuat oleh Propp; 2) mendistribusikan fungsi-fungsi tersebut ke dalam lingkaran atau lingkungan tindakan (speres of action) tertentu.

\subsection{Sumber Data}

Sumber data dalam penelitian ini berupa a) data primer, teks cerita rakyat Sobey Kororsri yang terdapat dalam buku Cerita Rakyat Jayapura untuk Generasi yang Sedang Berubah (2010), disusun oleh Alexander L. Griapon dkk., dan diterbitkan oleh Arika bekerja sama dengan Pemerintah Kabupaten Jayapura; dan b) data sekunder berupa data pendukung yang berasal dari sumber lain yang relevan (internet, koran, majalah, dan jurnal).

\section{Pembahasan}

\subsection{Ringkasan Cerita Rakyat Sobey Kororsri}

Kororsri adalah seorang putri laut dari Pulau Anus. Ia dan ibunya menghuni gua lautZambrar. Ia senang mengambil buah pisang yang tumbuh di PulauAnus. Pekerjaan tersebut dilakoninya setiap hari, walaupun ibunya sudah mengingatkannya untuk tidak mencuri buah pisang orang lain. Pemilik buah pisang tersebut adalah sepasang suami istri, Meterifet dan Fendesa. Saat itu hanya mereka berdua saja manusia yang menghuni Pulau Anus. Suatu ketika, suami istri tersebut bertengkar. Pertengkaran tersebut berakhir dengan kematian sang istri, Fendesa. Karena tidak dapat menerima usulan istrinya, Meterifet membunuh istrinya sendiri. Setelah peristiwa itu, Merifet menjelma menjadi batu karang yang tenggelam dalam laut. Sementara Fendesa berubah menjadi batu yang terbenam di dalam pasir.

Setelah kosong beberapa lama, sekelompok kaum laki-laki Papua menemukan pulau Anus yang penuh dengan tanaman peninggalan Merifet dan Fendesa. Mereka tidak sanggup untuk memanen buah 
yang tumbuh di pulau Anus. Hanya Kororsri yang setiap hari datang memanen atau memungut buahbuah yang jatuh di atas tanah. Sehingga, buah-buah yang berserakan itu segera menghilang dari pandangan mata. Pemandangan itulah yang menimbulkan keheranan orang-orang. Mereka mempertanyakan ke mana buah-buahan itu menghilang.

Akhirnya, mereka menyimpulkan bahwa ada makhluk lain yang sengaja datang memungut buah pisangyang jatuh. Sehingga, mereka mulaimemasang siasat untuk menjebak makhluk itu. Mereka memperalat Gegetan untuk mengintainya. Tak lama kemudian, muncullah Kororsri untuk memungut buah pisang itu. Hanya Gegetan yang melihat kedatangannya. Gegetan kemudian mengajukan permintaan untuk diberi banyak makanan, agar dia mau menceritakan apa yang terjadi dengan buah pisang itu. Kaum lakilaki menyanggupinya, Gegetan pun dapat makan sepuasnya. Setelah itu, Gegetan menceritakan tentang keberadaan Kororsri. Kaum laki-laki memutuskan untuk melakukan penyamaran. Mereka mengintai di dekat pohon-pohon pisang. Hanya Gegetan yang tidak melakukannya. Gegetan justru memasang perangkap di dekat terowongan menuju Gua Zambrar. Kaum laki-laki menjumpai Kororsri, mereka mengejarnya, namun tidak berhasil menangkapnya. Gegetan yang menunggunya di dekat goa yang dapat menangkapnya.

Gegetan menyerahkan Kororsri kepada Kenambai. Waktu terus berlalu, Kororsri dan Kenambai menikah. Mereka memiliki dua orang anak, putra dan putri. Konon, itulah peristiwa kelahiran pertama di Pulau Anus. Keluarga itu hidup dari hasil melaut. Ketika kedua anak itu ditinggalkan oleh orang tuanya di rumah, sesosok makhluk halus mengganggu mereka. Sehingga, Kororsri membawa kedua anaknya kembali ke Gua Zambrar.

Sepanjang jalan, Kororsri memerintahkan kepada anak laki-lakinya untuk melepaskan panah. Hal ini dimaksudkan supaya jejak langkah mereka dapat diketahui oleh Kenambai. Benar saja, Kenambai mendapatkan firasat yang aneh. Ia bergegas kembali di rumahnya dan tak lagi mendapati anak istrinya di sana. Ia hanya mendapati makhluk halus, nenek penjaga tungku api. Ia pun menikam nenek itu hingga tewas dan bergegas mencari keberadaan keluarganya. Ia menuju ke laut dan kembali mengayuh perahunya. Ia memanggil-manggil anak-anaknya melalui lagu. Karena mendengar suara panggilan ayahnya, putranya melepaskan anak panah dan menghantam perahu Kenambai. Seketika Kororsri muncul di dalam perahu suaminya. Kenambai memohon agar ia dapat ikut serta dengannya untuk hidup bersama. Kororsri menarik suaminya dan mereka menenggelamkan diri ke dasar laut. Mereka sekeluarga hidup di dalam Gua Zambrar, sementara perahu Kenambai berubah menjadi batu karang di permukaaan laut Daiwer, dekat Gua Zambrar.

\subsection{Morfologi Cerita Rakyat Sobey Kororsri}

\subsubsection{Analisis Fungsi}

Dalamanalisis ini, fungsi-fungsi pelaku ditampilkan hanya dalam bentuk pokok yang disertai lambang dan ringkasan isi cerita. Adapun hasil analisis fungsi dalam cerita rakyat Sobey Kororsri adalah sebagai berikut.

(0) Situasi Awal (lambang: $\alpha$ )

Situasi awal cerita ini ketika sepasang suami istri, Merifet dan Fendesa menanam pisang di atas Pulau Anus. Tanaman mereka tumbuh subur dan berbuah banyak. Setiap hari Kororsri datang untuk memungut dan membawa pulang buah pisang yang berjatuhan di atas tanah. Situasi itulah yang menjadi pemicu awal untuk pergerakan cerita sehingga munculfungsi-fungsi berikut.

\section{(1) Interdiction = larangan, simbol: $\gamma$}

Kororsri setiap hari mencuri buah pisang milik pasangan suami istri, Meterifet dan Fendesa. Kelakuan Kororsri itu mendapat larangan dari ibunya. Namun, dia tetap tidak peduli.

\section{(2) Lack= kekurangan (kebutuhan), simbol: a}

Setelah tanaman Meterifet dan istrinya tumbuh, Fendesa tetap merasa perlu menanam sagu sebagai makanan pokok mereka. Lalu ia mengajukan usul untuk menanam sagu di atas pulau yang mereka tempati itu. Namun sayangnya, suaminya tidak menyetujuinya. 


\section{(3) Villainy = kejahatan, simbol:A}

Mendadak sepotong kayu kering menghantam kepala Fendesa, lalu perempuan itu tak berdaya. Kekerasan dalam rumah tangga terjadi di tengah Pulau Anus saat belum ada orang lain yang dapat menyaksikan kekerasan itu atau melerainya.

\section{(4) Transfiguration = penjelmaan, simbol T}

Meterifet meninggalkan istrinya seorang diri di antara tanaman pisang, ia berjalan ke batas pantai lalu terbenam dalam pasir laut yang terhempas ombak, sehingga seluruh tubuhnya terbujur membeku menjadi batu karang yang kemudian menghilang ke dalam dasar laut, hanya menyisakan bentuk perangkat lunak kelaki-lakiaan yang menonjol menjadi batu karang laut yang bertahan sepanjang masa. Fendesa berubah menjadi batu yang terbenam dalam pasir pada hamparan tumbuhan pisang yang menonjolkan perangkat lunak keperempuanannya abadi di atas pulau anus.

(5) The initial misfortune or lack is liquidated = Kekurangan (kebutuhan) terpenuhi, simbol: K

Buah-buah sukun dan pisang menjadi makanan burung-burung dan jenis binatang penggeret, selebihnya berjatuhan menghiasi permukaan tanah pulau karang itu. Pulau yang kaya dengan pisang dan sukun dan yang tak kuat untuk dipanen oleh para lelaki pendatang baru itu. Hanya Kororsri, putri laut penghuni Goa Zambrar yang memberanikan diri untuk memungut buah-buah pisang walaupun ia ditegur berkalikali oleh induknya.

\section{(5. a) Reconnaissance $=$ pengintaian, simbol: $\varepsilon$}

Sekelompok laki-laki Papua yang menemukan pulau ini merasa kewalahan memanen dan memungut buahbuahan yang jatuh. Namun, mereka dikejutkan oleh situasi dimana buah-buahan yang selalu berserakan itu selalu menghilang setiap hari. Mereka penasaran akan siapa orang yang datang memungutnya. Tanpa mengusik pohon-pohon dan sisa peninggalan hasil kerja Kororsri, seluruh penghuni kampung membungkus seorang laki-laki yang bernama Gegetan dalam balutan daun pisang kering yang ditempatkan pada pohon-pohon pisang di dekat tempat lintasan setapak bekas pijatan manusia. Ketika permukaan laut memantulkan sinar matahari pagi, mata Gegetan bertambah silau tertimpa cahaya yang lebih terang, cahaya yang bergerak dari laut ke daratan, kemudian bergerak semakin mendekati jalan setapak di dekat rumpun-rumpun pisang tempat Gegetan bersembunyi.

(6) Mediation, the connective incident = perantaraan, peristiwa penghubung, simbol: B

Terang berlalu bersama sesosok putri yang berjalan menuju sebatang pohon pisang, ia menegakkan kepalanya memandang ke setandan buah pisang yang sarat berwarna kuning, mencondongkan tubuh ke tegakan batang pisang tepat di depannya, lalu menggoncang pohon sampai buah-buah itu berhamburan ke pasir. Ia memungut dalam kantong kombon dan menarik menuju laut, lalumenghilang dibalik gulungan ombak laut pantai Pulau Anus.

(7) The first function of the donor = fungsi pertama donor (pemberi), simbol: D

Gegetan adalah orang terhina yang selalu diabaikan oleh kaum lelaki Pulau Anus masa itu, ketika para lelaki Anus memperoleh ikan laut atau daging binatang buruan, Gegetan diberikan bagian tulang-tulang sisa peninggalan makanan mereka. Setiap masakan papeda yang disantap orang Anus selalu menyisakan kerak papeda yang kering dan keras untuk Gegetan.

(8) Delivery = penyampaian (informasi), simbol: $\xi$ Setelah Gegetan melakukan pengintaian, orang kampung ingin segera mengetahui apa hasil pengintaiannya. Namun Gegetan tak serta merta menyampaikan apa yang dilihatnya tentang keberadaan putri laut tersebut. Terlebih dahulu ia mengajukan permintaan kepada orang kampung. Ia meminta untuk disediakan makanan yang banyak, setelah makan, barulah ia mau menyampaikan informasi yang diinginkan oleh orang kampung. Orang kampung menyanggupinya. Mereka segara memenuhi permintaan Gegetan. Setelah Gegetan makan dengan lahapnya, barulah Gegetan menceritakan apa yang dilihatnya selama kegiatan pengintaiannya. 
(9) Fraud = penipuan (tipu daya), simbol: $\eta$

Mendengar ucapan Gegetan yang terakhir, seluruh kaum laki-laki mempersiapkan rencana untuk menjerat perempuan itu pada pagi hari berikutnya. Malam hari, mereka membalut diri dengan daun pisang kering yang masih tergantung pada tangkal setiap pohon pisang sebanyak jumlah lelaki Pulau Anus. Hanya Gegetan yang tidak melakukan penyamaran, ia berenang ke laut dan berjaga pada sebatang kayu dari pohon besar dekat lintasan ujung terowongan Goa Zambrar.

(10) Pursuit, chase = pengejaran, penyelidikan, simbol: $\operatorname{Pr}$

Putri laut itu muncul bersama terbitnya matahari yang memantulkan cahaya pada permukaan laut dan daratan Pulau Anus, ia melompat-lompat di antara tegakan pohon pisang, lalu menggoyang-goyang sebatang pisang dan memungut buah pisang yang berjatuhan, kaum laki-lakiAnus melepaskan diri dari daun-daun pisang tempat persembunyian dan menyerbu sang putri jelita, namun tak ada seorang pun yang dapat menangkap Kororsri, makhluk laut bertubuh ramping penuh sejenis cairan licin bagai belut. Kali ini ia lolos dari kaum laki-laki yang berjaga di daratan pulau karang itu.

(11) Struggle= berjuang, bertarung, simbol: $\mathrm{H}$ Kororsri berenang dengan cepat menuju Goa Zambrar untuk kembali ke tempat perteduhan bersama induknya. Seluruh pikiran dan tenaganya hanya terkonsentrasi untuk lolos dari kejaran manusia yang dianggapnya sudah ditinggalkan di daratan pulau itu, selanjutnya hanya jarak dan rintangan alam untuk mencapai dasar Zambrar. Ketika ia melompat di permukaan air laut untuk masuk ke pintu goa, rambutnya yang terurai tersangkut pada sebuah benda yang sengaja disodorkan dari atas batang kayu pohon di permukaan air oleh tangan Gegetan yang sudah menunggu dari tadi. Sebilah pisau belati tulang kaki kangguru menahan kaki sang putri laut, sehingga tubuhnya tertahan tak berdaya, ia tertangkap oleh Gegetan.

Gramatika, Volume II, Nomor 2, Juni-Desember 2014
(12) Rescue = penyelamatan, simbol: Rs

Gegetan menyerahkan Kororsri kepada Kenembainya itu dengan mengucapkan terima kasih atas segala kebaikan terhadap dirinya, kemudian berjalan pergi meninggalkan kumpulan orang kampung yang tidak dapat mengharapkan sesuatu dari Gegetan lagi.

(13) Wedding = perkawinan (dan naik tahta), simbol $\mathrm{W}$

Waktu terus berlalu, Kororsri memperoleh seorang putra dan seorang putri blasteran darat dan laut. Putri laut dan suaminya hidup sebagai peladang dan penangkap ikan di pantai dengan cara "bebatu".

(14) The hero's reaction= reaksi pahlawan, simbol: $\mathrm{E}$

Segera Kororsri meletakkan air timbahan itu dan melangkahkan kaki ke dalam rumah panggung, membersihkan rumah dari kotoran yang disebut anak lakilakinya mengulangi perkataan perempuan misteri tungku api dapur rumah itu. Seluruh halaman rumah dibersihkan, lalu ia menyiapkan makanan dan memberi makan kedua anaknya, bagiannya dilahap sampai habis, hidangan makanan untuk suaminya ditinggalkan di atas tempat meletakkan makanan. Segera Kororsri memberitahukan kepada anaknya bahwa mereka akan pulang ke tempat nenek mereka.

(15) Spacial translocation = perpindahan (tempat), simbol: G

Segera ia mengisi kantong itu dengan pinang, sirih, dan kapur. Kororsri memberikan beberapa batang anak panah yang terbuat dari daun sagu dan tombak kepada putranya, lalu mereka berjalan meninggalkan rumah menuju Wereswer di ujung timur Pulau Anus, dan menyeberangi pulau sewaktu permukaan air laut surut. Tujuan kepergian mereka adalah Sir, batuan karang yang terletak dekat Pulau Anus, tempat nenek kedua anak itu berada dalam Goa Zambrar.

\section{(16) Marking = penandaan, simbol: J}

Kororsri menjelaskan kepada kedua anaknya yang memperhatikan dengan sungguh-sungguh ucapan ibundanya. Kororsri menyuruh putranya melepaskan 
satu anak panah kendeis pada buah tumbuhan pantai yang disebutnya tup fow, buah majut dekat semburan ludah pinang Kororsri yang membekaskan warna merah pada pasir putih, kemudian dia dan kedua anaknya melanjutkan perjalanan dengan meninggalkan bekas pijakan kaki di atas pasir yang ditujukan untuk sang Kenambai yang belum mengetahui kepergian mereka. Perjalanan mereka terhenti di suatu tempat yang disebut Mefra, Kororsri memerintahkan putranya melepaskan anak panah kendeis yang mengena pada tiga buah majut dari tangkai pada dahan pohon yang rindang. Buah-buah itu sebagai simbol dari Kororsri dan dua anaknya, ia menyembur ludah pinang ke atas permukaan pasir Mefra.

\section{(17) Return=kepulangan (kembali), simbol: $\downarrow$}

Kororsri dan anak-anaknya tiba di atas ujung terowongan Goa Zambrar. Kororsri memanggil ibunya yang ada di dasar laut untuk menyambut cucu-cucunya. Kororsri segera melepaskan pegangannya dari putranya yang disambut dalam dekapan sang nenek, nenek menariknya ke dalam goa. Begitu pun dengan anak perempuan Kororsri. Saat yang sama Kororsri turun mengikuti induk dan putrinya.

(18) Departure $=$ keberangkatan (kepergian), simbol: $\uparrow$

Kenembai turun dari rumah mengarahkan langkah kakinya mengikuti pikiran ke ujung timur kampung hingga tiba di Daiwer, dari tempat itu ia menyusuri jalan pantai Sir dan menemukan jejak hingga ke Mefra.

(19) Punishment = hukuman (bagi penjahat), simbol: U

Kenembai kembali ke rumah menemui perempuan tungku api, ia mengambil tombak penikam binatang buruan yang disebut domkei, lalu menikam makhluk tungku api itu pada lambungnya hingga tewas di dalam rumah itu, rumah yang ditinggalkannya bersama jazad sang pembawa sial itu untuk selamanya.

\section{(20) Solution $=$ penyelesaian (tugas), simbol: $\mathrm{N}$}

Kenembai memohon supaya ia dibawa serta ke Goa Zambrar, agar ia dapat hidup berkumpul kembali ber- sama dengan keluarganya. Tiba-tiba Kororsri menarik tangan suaminya, menjatuhkan diri bersamasama dari perahu ke atas permukaan air laut, dan menyelam tak kembali lagi. Perahu itu tetap tinggal di permukaan laut Daiwer, dekat Goa Zambrar, hingga menjadi batu karang laut sampai selamanya.

\section{(21) Situasi akhir (lambang: X)}

Situasi akhir yang menutup cerita ini adalah keluarga Kenembai dan Kororsri dapat berkumpul kembali. Akhirnya, mereka hidup bersama di Goa Zambrar.

\subsubsection{Fungsi Skema}

Jika cerita rakyat Sobey Kororsri disusun dalam bentuk skema, kerangka cerita yang membentuk strukturnya akan tampak seperti berikut.

$(\alpha): \gamma$ a A T K $\varepsilon$ B D $\xi \eta \operatorname{PrH} \operatorname{Rs}$ W E G $\downarrow \downarrow \mid$ UN : (X)

\subsubsection{Pola Cerita}

Setelah unsur-unsur penting dan unsur-unsur penjelasnya ditunjukkan, dalam cerita ini dapat ditemukan pola-pola tertentu. Propp (dalam Suwondo, 2011:68), satu cerita (komponen) tertentu dapat ditandai oleh satu perkembangan atau pergerakan yang diawali oleh penetralan (tindakan) dimulai dan diakhiri dengan mencapai tempat tujuan setelah melalui fungsi-fungsi perantaraan. Setelah mencermati fungsi-fungsi pelaku di atas, maka pola yang ditemukan berdasarkan cerita ini adalah sebagai berikut.
I. $\gamma--\mathrm{W}$
II. $\mathrm{E}-\uparrow$
III. $\mathrm{U}-\mathrm{N}$

Secara umum, keempat pola ini menunjukkan bahwa alur cerita adalah alur forward (maju). Karena keterkaitan peristiwa yang terbentuk dalam cerita terus berkembang (maju). Pola I merupakan bagian awal cerita, pola II adalah isi cerita, dan pola III adalah bagian akhir cerita.

\subsubsection{Distribusi Fungsi di Kalangan Pelaku}

Menurut Propp (dalam Suwondo, 2011: 69--70), ke-31 fungsi yang menjadi kerangka pokok cerita rakyat Sobey Kororsridapat didistribusikan ke dalam lingkaran tindakan (speres of action). Ada tujuh 
lingkaran tindakan dalam cerita rakyat. Jadi, setiap lingkaran (lingkungan) tindakan dapat mencakupi satu atau beberapa fungsi. Namun, cerita rakyat Sobey Kororsri hanya memiliki enam lingkaran tindakan, yaitu:

(1) Lingkungan aksi penjahat: a, A, T, K, $\varepsilon, \eta, P r$, $\mathrm{U}$

(2) Lingkungan aksi donor (pembekal): $\uparrow$

(3) Lingkungan aksi pembantu: D, $\xi$, Rs

(4) Lingkungan aksi seorang putri dan yang diinginkannya: $\mathrm{B}, \mathrm{H}$

(5) Lingkungan aksi perantara: Rs

(6) Lingkungan aksi pahlawan: B, H, W, E, G, $\mathrm{J}, \downarrow, \mathrm{N}$

(7) Lingkungan aksi pahlawan palsu: -

\section{Penutup}

\subsection{Simpulan}

Berdasarkan pembahasan morfologi cerita rakyat Sobey Kororsri di atas, peneliti mengambil beberapa simpulan sebagai berikut.

- Terdapat21(duapuluhsatu)fungsinaratifdalam cerita rakyat Sobey Kororsri.

- $\quad$ Fungsi skema cerita rakyat Sobey Kororsri: $(\alpha): \gamma$ a A T K $\varepsilon$ B D $\xi \eta \operatorname{PrHRs}$ W GJ $\downarrow \uparrow U$ $\mathrm{N}:(\mathbf{X})$

- Terdapat 3 (tiga) pola cerita di dalamnya. Ketiga pola cerita cerita rakyat Sobey Kororsri menunjukkan bahwa alur cerita adalah alur forward (maju). Karena keterkaitan peristiwa yang terbentuk dalam cerita terus berkembang (maju).

- Cerita rakyat Sobey Kororsri memiliki6(enam) lingkaran tindakan (speres of actions).

Semakin banyak fungsi yang ditunjukkan dalam cerita, menunjukkan kompleksitas budaya masyarakatnya. Karena fungsi-fungsi tersebut merupakan rangkaian peristiwa yang terjadi dalam cerita. Di dalam fungsi-fungsi tersebut, juga terdapat nilai moral yang mengikatnya secara utuh. Nilai-nilai tersebut antara lain 1) saling menghargai hak dan kewajiban masing-masing; 2) patuh kepada orang tua; 3) kegotongroyangan; 4) tanggung jawab; dan 5) kerja keras.

\subsection{Rekomendasi}

Peneliti merekomendasikan agar kegiatan penelitian sastra, khususnya sastra lisan dalam genre apapun di tanah Papua ini dapat dilaksanakan secara lebih terarah, bertahap, serta berkelanjutan demi pembangunan mental masyarakat Sobey di Kabupaten Sarmi, Papua sebagai pemilik kebudayaan, dan bangsa Indonesia secara menyeluruh.

\section{Daftar Pustaka}

Endraswara, Suwardi. 2013. Teori Kritik Sastra: Prinsip, Falsafah, dan Penerapan. Yogyakarta: CAPS.

Griapon, Alexander L., et.al. 2010. Cerita Rakyat dari Jayapura untuk Generasi yang Sedang Berubah. Jayapura: Arika dan Pemkab Jayapura.

Lekitoo, Hanro Y. dan Djekky R. Djoht. 2005. Sejarah Sarmi. Sarmi: Pemerintah Kabupaten Sarmi.

Lestari, Ummu Fatimah Ria. 2013. Morfologi Cerita Rakyat Ormu (Sebuah Telaah Teori Propp). Multilingual, XII 1 128-139.

Ratna, Nyoman Kutha. 2006. Teori, Metode, dan Teknik Penelitian Sastra: Dari Strukturalisme Hingga Postrukturalisme Perspektif Wacana Naratif. Yogyakarta: Pustaka Pelajar.

Samakori, Habel, et.al. 2012. Etnolinguistik sebagai Proses Pengenalan Sejarah dan Perkembangan Bahasa Lokal di Kabupaten Sarmi. Laporan Penelitian. Sarmi: Bappeda Kabupaten Sarmi bekerja sama dengan Universitas Cenderawasih.

Susanto, Dwi. 2012. Pengantar Teori Sastra: Dasar-Dasar Memahami Fenomena Kesusastraan. Yogyakarta: CAPS.

Suwondo, Tirto. 2011. Studi Sastra: Konsep Dasar dan Penerapannya pada Karya Sastra. Yogyakarta: Gama Media.

Taum, Yoseph Yapi. 2011. Studi Sastra Lisan: Sejarah, Teori, Metode, dan Pendekatan Disertai Contoh Penerapannya. Yogyakarta: Lamera.

Teeuw, A.1988. Sastra dan Ilmu Sastra: Pengantar Teori Sastra. Jakarta: Pustaka Jaya. 